\title{
Dia Mundial sem Tabaco e Dia Nacional de Combate ao Fumo:Catálogo de Campanhas 1997-2017
}

doi: https://doi.org/10.32635/2176-9745.RBC.2018v64n2.88

World no Tobacco and National no Smoking Day: Campaign Catalogues 1999-2017

Día Mundial sin Tabaco y Día Nacional de Combate al Humo: Catálogos de Campañas, 1999-2017

Instituto Nacional de Câncer José Alencar Gomes da Silva. Rio de Janeiro: INCA; 2017. 60p.

ISBN 978-85-7318-333-7 (versão impressa)

ISBN 978-85-7318-332-0 (versão eletrônica)

\section{Andréa Ramalho Reis Cardoso}

Esta publicação realiza um resumo histórico das campanhas (Dia Mundial sem Tabaco e Dia Nacional de Controle do Tabagismo), coordenadas pelo Instituto Nacional de Câncer José Gomes de Alencar (INCA/MS), que, desde o final da década de 1980, sob a ótica da promoção da saúde, é o responsável pela gestáo e governança do controle do tabagismo no Brasil coordenando um conjunto de ações nacionais específicas que compóem o Programa Nacional de Controle do Tabagismo (PNCT).

Buscamos realizar um breve histórico das campanhas realizadas, imagens e materiais utilizados nas campanhas do Dia Mundial sem Tabaco e Dia Nacional de Combate ao Fumo.

Com o intuito de disseminar ainda mais o conhecimento sobre os malefícios do tabagismo, são elaboradas as campanhas pontuais como: Dia Mundial sem Tabaco - 31 de maio e Dia Nacional de Combate ao Fumo - 29 de agosto. Essas campanhas de massa são desenvolvidas parar trazer a discussão temáticas importantes referentes ao tema tabaco e seus assuntos correlacionados.

O tabagismo integra o grupo dos transtornos mentais e comportamentais em razão do uso de substância psicoativa na Revisão da Classificação de Doenças (CID-10, 1997), e é a maior causa isolada evitável de adoecimento e mortes precoces em todo o mundo.

O PNCT tem, portanto, o objetivo de reduzir a prevalência de fumantes e a consequente morbimortalidade relacionada ao consumo de derivados do tabaco no Brasil, seguindo um modelo lógico no qual açôes educativas, de comunicação, de atenção à saúde, junto com o apoio à adoção ou cumprimento de medidas legislativas e econômicas, possam se potencializar para prevenir a iniciação do tabagismo, principalmente entre adolescentes e jovens; para promover a cessação de fumar; e proteger a população da exposição à fumaça ambiental do tabaco e reduzir o dano individual, social e ambiental dos produtos derivados do tabaco.

Como parte de seus objetivos, o PNCT articula essas açóes comemorativas de forma articulada com as secretarias estaduais e municipais de Saúde dos 26 Estados e Distrito Federal, envolvendo, também, a sociedade civil organizada.

O Dia Mundial Sem Tabaco - 31 de maio - foi criado em 1987 pela Organização Mundial da Saúde (OMS), com o objetivo de atrair a atenção do mundo sobre a pandemia do tabagismo, sobre as doenças e mortes evitáveis a ele relacionadas.

Desde então, anualmente, a OMS articula em todo o mundo a comemoração do Dia Mundial sem Tabaco, definindo um tema correlato ao tabagismo, a ser abordado pelos 191 países membros, com a finalidade de pôr em evidência as diferentes interfaces ou problemáticas do consumo de tabaco e, assim, engajar diferentes atores sociais no controle do tabagismo.

O Dia Nacional de Combate ao Fumo - 29 de agosto, criado por intermédio da Lei Federal nº 7.488 , é comemorado desde de 1986. Essa comemoração faz parte do conjunto de açóes do PNCT e tem como objetivo alertar a populaçấo em geral e, especialmente o jovem, sobre os malefícios advindos do uso dos produtos do tabaco e os benefícios alcançados por meio da cessação de fumar.

'Especialização em Pedagogia Empresarial. Instituto Nacional de Câncer José Alencar Gomes da Silva (INCA). Rio de Janeiro (RJ), Brasil. E-mail: areis@inca.gov.br. Orcid ID: https://orcid.org/0000-0002-1881-4382

Endereço para correspondência: Rua Marques de Pombal, 125 - $5^{\circ}$ andar - Centro. Rio de Janeiro (RJ), Brasil. 
A cada ano, são trabalhados diversos temas que se relacionem de alguma forma com o controle do tabagismo. Por ser um tema relevante da população e por possuir diferentes aspectos correlacionados, o PNCT se esforça para que a população possa compreender, por meio dessas campanhas, a grande variedade de perigos a que são expostos.

As campanhas têm como objetivo reforçar as ações nacionais de sensibilização e mobilização da população para os danos sociais, políticos, econômicos e ambientais causados pelo tabaco; alertam também sobre as doenças e mortes evitáveis relacionadas ao tabagismo. Podemos citar como temas correlacionados: custos, problemas ambientais, questóes culturais de uso, tabagismo passivo, pontos de venda, embalagens dos produtos, produtos derivados do tabaco, estratégias de disseminação dos produtos etc.

Nessa perspectiva, o Dia Mundial sem Tabaco e o Dia Nacional de Combate ao Fumo oferecem uma grande oportunidade para trazer algumas reflexóes sobre esse tema para toda a sociedade brasileira, sobretudo para profissionais de saúde e de educação, formuladores de políticas públicas e legisladores brasileiros. Mediante os temas trabalhados, é possível, a partir das discussóes, sugerir açóes necessárias para um efetivo controle do tabagismo ao propor estratégias e políticas públicas consistentes para o controle do tabaco.

Resumidamente, podemos listar os objetivos gerais das Campanhas: Dia Mundial sem Tabaco e Dia Nacional de Combate ao Fumo:

Sensibilizar a comunidade em geral sobre os malefícios do consumo dos produtos derivados do tabaco e sobre as estratégias da Industria do Tabaco; Gerar uma grande discussão sobre o problema do tabagismo em seus diferentes aspectos: malefícios à saúde de fumantes, questóes relacionadas a preços e impostos, comércio ilícito, tabagismo passivo, estratégias da indústria, prejuízos ao meio ambiente e benefícios ao se deixar de fumar; Mobilizar diferentes setores da comunidades: comunidade em geral; crianças, jovens, adolescentes e adultos; formadores de opiniáo; legisladores; profissionais de diferentes áreas (setores da educação, saúde, comunicação) para colaborarem com medidas de controle do tabaco em nosso país; Informar à população sobre os danos ocasionados pelo tabaco, sobre as estratégias de divulgação desses produtos; estimular uma visão crítica do problema tabaco; Reforçar parcerias entre o governo federal, estadual e municipal na adesão a Implantação do PNCT e da CQCT; Mobilizar o apoio necessário para respaldar/fazer valer as políticas vigentes, como, por exemplo: de ambientes livres de tabaco.

Os temas escolhidos têm como objetivo levantar o debate pelos diferentes segmentos da sociedade e reforçar também uma mensagem voltada para grupos específicos que possam dar alguma contribuiçẫo no controle do tabagismo; ou seja, legisladores e formadores de opiniâo. Este trabalho busca engajar a sociedade em açôes de mobilização social que impulsionem a criação de leis e medidas de apoio às açôes de controle do tabagismo em todo o país.

Esta publicaçáo possibilitou a realizaçáo de um levantamento histórico sobre todas as campanhas estruturadas nos últimos anos e servirá como fonte de consulta e apoio para a criação de outras campanhas que venham colaborar com a melhora da qualidade de saúde da populaçáo brasileira.

\section{RFERÊNCIAS}

1. Instituto Nacional de Câncer José Alencar Gomes da Silva [Internet]. Rio de janeiro: INCA; @1996-2018 [citado 2017 Abr 22] Programa Nacional de Controle do Tabagismo; [aprox. 2 telas]. Disponível em: http://www2.inca.gov.br/wps/ $\mathrm{wcm} /$ connect/acoes_programas/site/home/nobrasil/programa-nacional-controle-tabagismo.

2. Organización Mundial de la Salud [Internet]. Genebra: WHO; @2017 [citado 2017 Abr 21]. Día Mundial Sin Tabaco: el tabaco, una amenaza para el desarrollo; [aprox. 2 telas]. Disponível em: http://www.who.int/campaigns/no-tobaccoday/2017/event/es/. 